\section{Commentary: Your eyes can deceive you; don't trust them}

\author{
Rabbiya Hanif, MBBS, and Awais Ashfaq, MD
}

The Chiari network, found infrequently in the right atrium, is a fenestrated, net-like embryonic remnant from failure of resorption of the right-sided sinus venosus valve. Developmentally, the right valve of the sinus venosus evolves into 2 valves: the valve of the inferior vena cava (Eustachian valve) and the valve of the coronary sinus (Thebesian valve). ${ }^{2}$ Hans Chiari, an Austrian pathologist, first described this phenomenon in 13 human right atria in $1897,{ }^{1}$ and the prevalence has been reported to be $2 \%$ to $14 \%{ }^{3}$ Usually it has no significance, but in some cases, it can lead to diagnostic confusion, causing thromboembolism, endocarditis, arrhythmias, and so on.

In the current issue of this Journal, Manerikar and colleagues ${ }^{4}$ report a unique case of a patient presenting with Chiari network and a patent foramen ovale (PFO) who suffered a stroke and was treated surgically using a minimally invasive approach. Another conundrum in this case was the suspicion of a left heart mass that clouded the picture of what caused the stroke and how best to treat it.

The authors are to be commended on their clinical reasoning and problem-solving, but although undoubtedly novel and unique in its presentation, we must be careful not to apply too broadly the conclusions from this case report. First, the Chiari network is a relatively common benign clinical finding and may be associated with a PFO in the general population. If the authors had not found the left-sided mass, their urgency to proceed with surgical intervention would perhaps been different and perhaps a percutaneous option would have been considered. The choice of

From the Cardiovascular Surgery, Heart Institute, Johns Hopkins All Children's Hospital, St Petersburg, Fla.

Disclosures: The authors reported no conflicts of interest.

The Journal policy requires editors and reviewers to disclose conflicts of interest and to decline handling or reviewing manuscripts for which they may have a conflict of interest. The editors and reviewers of this article have no conflicts of interest.

Received for publication Dec 6, 2021; revisions received Dec 6, 2021; accepted for publication Jan 7, 2022; available ahead of print Jan 11, 2022.

Address for reprints: Awais Ashfaq, MD, Cardiovascular Surgery-Heart Institute, Johns Hopkins All Children's Hospital, 501 6th Ave South, St Petersburg, FL 33703 (E-mail: aashfaq1@jhmi.edu).

JTCVS Techniques 2022;11:48

2666-2507

Copyright (c) 2022 The Author(s). Published by Elsevier Inc. on behalf of The American Association for Thoracic Surgery. This is an open access article under the CC BY-NC-ND license (http://creativecommons.org/licenses/by-nc-nd/4.0/).

https://doi.org/10.1016/j.xjtc.2022.01.003

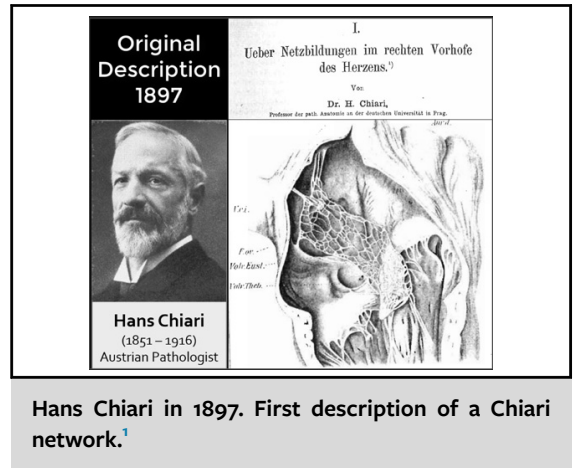

CENTRAL MESSAGE

Chiari network leading to a stroke treated with a minimally invasive approach is discussed.

the surgical approach via right thoracotomy is logical, as it affords appropriate visualization to both the right and left atrium, avoiding manipulation of the heart before crossclamping. Nonetheless, their approach in this clinically unique patient can certainly not be generalized, and perhaps other methods of treatment can be argued, namely, improved cross-sectional imaging to study the left-sided mass, the use of anticoagulation, and defining the landmarks of the PFO to consider a percutaneous approach. All of these are considerations for this rare presentation, each with its limitations. However, what we learn from this case is, even apparent benign conditions should be thoroughly studied and surgical interventions with less morbidity and quicker recovery can be undertaken to achieve an adequate result.

\section{References}

1. Chiari H. Ueber netzbildungen im rechten vorhofe des herzens. Beitr Pathol Anat. 1897;22:1-10.

2. Bhatnagar KP, Nettleton GS, Campbell FR, Wagner CE, Kuwabara N, Muresian H. Chiari anomalies in the human right atrium. Clin Anat. 2006;19: 510-6.

3. Islam AM, Sayami LA, Zaman S. Chiari network: a case report and brief overview. J Saudi Heart Assoc. 2013;25:225-9.

4. Manerikar A, Malaisrie SC. Chiari network and patent foramen ovale associated with stroke. J Thorac Cardiovasc Surg Tech. 2022;11:45-7. 